\title{
Investigation of the effect of gaps between the blades of open flume Pico hydro turbine runners
}

\author{
D. Adanta ${ }^{1}$ Budiarso $^{1}$, Warjito 1 , T. M. I. Mahlia ${ }^{2}$ \\ ${ }^{1}$ Department of Mechanical Engineering, Universitas Indonesia, \\ Kampus Baru UI Depok 16424, Indonesia \\ Email: dendyadanta@ymail.com; budiarso@ui.ac.id; warjito@eng.ui.ac.id \\ Phone: +62-21-7270032; Fax: +62-21-7270033 \\ ${ }^{2}$ School of Systems, Management and Leadership, \\ Faculty of Engineering and Information Technology, \\ University of Technology Sydney, NSW 2007, Australia \\ Email: TMIndra.Mahlia@uts.edu.au
}

\begin{abstract}
This study analyzes the impact of gap size for two reaction turbine runners, to provide recommendations for the maximum of design and manufacture of open flume turbines. Two number of blades were tested: five blades (Runner A) and six blades (Runner B). Three methods were used for this investigation: the theoretical analysis to design the turbine, experiments to determine the actual turbine performance and to validate the design and the manufacturing processes, and computational fluid dynamics to study physical phenomena and re-check runner velocity triangles. From the results, it can be seen that gaps between blades can alter the velocity vector at the outlet, thus they can unbalance the runner rotation; this could cause cavitation as a result of the decrease in the velocity of the water on the outlet with the increase in pressure. This pressure increase causes the draft tube not to function optimally, and, consequently, the torque decreases because the water pressure in the draft tube approaches the atmospheric pressure. Two conditions must be satisfied to maximize the turbine performance: minimizing the radial velocity at the outlet by flow after passing through the turbine is made swirl; and avoid forming gaps between the blades.
\end{abstract}

Keywords: Open flume turbine; velocity triangle; Euler equation; energy conversion.

\section{INTRODUCTION}

The economy of Indonesia has grown rapidly in the last two decades, thus increasing the country's energy demands; the pattern of energy consumption, energy scenario, and sustainable energy in the country has been extensively discussed by Hasan et al. [1,2]. In 2012, Indonesia's population was more than 230 million. The country uses the equivalent of 893 thousand barrels of oil, and is ranked 13th in the world among primary energy users, being the third largest emitter of greenhouse gases in Asia (392.9 million tonnes of $\mathrm{CO}_{2}$ ). In response to this issue, Indonesia is trying to develop alternative and renewable energy, including geothermal [3], bioenergy [4], biodiesel [5-8], and bioethanol [9-11]. The country 
also actively promotes energy efficiency and sustainable energy programs to help prevent global warming [12-15].

Increasing the electrification ratio is an effective way to improve living standards [16]. In some developing countries, the electrification ratio is increased using off-grid power plants to serve small local communities that are not served by the national electrical grid [17]. In this context, pico hydro is a potentially effective strategy, especially because of its low pay back time and low life-cycle cost per kilowatt compared to other electric power systems [18]. A pico hydro plant is defined as an hydropower plant with a power capacity below $5 \mathrm{~kW}$ [18]. Pico hydro is easy to manufacture and operate, and its design and construction materials (e.g., wood for water wheels) are readily available in remote areas. Therefore, pico hydro is one of the most appropriate energy solutions for remote areas [19].

However, the main problems with the development of pico hydro in Indonesia is its investment cost and its low and unstable efficiency; these problems are due to low income per capita and a lack of public knowledge within the community. Pico hydro turbines like Pelton, Turgo, Cross-flow, Francis, and Kaplan are not cost-effective and are quite complex to install using local manufacturers and expertise [20]. On the other hand, water wheels and propeller turbines are feasible and low-cost alternatives [21]; this study focuses on propeller turbines.

Propeller turbines are reaction turbines with adjustable or fixed rotor blades [22]. When the blade positions can change according to the flow rate and head, propeller turbines are called Kaplan turbines. The hydraulic range for Kaplan turbines with adjustable blades is $30-80 \mathrm{~m}$, and the range for propeller turbines is 5-30 $\mathrm{m} \mathrm{[22].}$

An open flume turbine (OFT) is a propeller turbine that can generate power with an average efficiency of more than 50\% [22]. OFT guide vanes are fixed, thus no dam is needed, as the inlet goes directly in the flume. The advantage of the OFT compared to Kaplan and propeller turbines is its lower investment cost due to its simple blade shape and fixed guide vane. The OFT can be effectively applied for power output under $5 \mathrm{~kW}$ with less than $5 \mathrm{~m}$ head [23]. In addition, the maintenance, installation, and operational costs of OFTs are relatively easier when compared with Kaplan turbines. This is why some pico hydro turbine researchers use OFTs for remote areas [24-27].

Several previous studies have examined ways to improve the performance of propeller turbines. For example, Amromin [28] studied the cavitation of propeller turbines, and Simpson and Williams [29] researched blade design to optimize the performance of a propeller turbine. Arrieta et al. [30] observed the maximum deformation received by the propeller blade under various conditions. A study by Alexander et al. [31] determined the effect of specific speeds $\left(n_{s}\right)$ of the propeller turbine on the power generated; they concluded that the specific speed is related to the power generated by the turbine, and that the specific speed of 242 achieved the highest hydraulic efficiency of 75\%. Singh and Nestmann [32] investigated the relative dominance of the size and number of blades on a turbine efficiency and concluded that the number of blades was more influential than blade size on the power generated, due to the slip effect and the loss mechanism on the runner. Swiderski et al. [33] developed a method for optimizing the blade shape to improve a turbine efficiency and suppress the cavitation of the turbine blades. Ramos et al. [34] analyzed four penstock systems commonly used with propeller turbines, and recommend that open-channel systems, such as the open flume, should be used, since their hydraulic losses are smaller than the losses 
of the Kaplan turbines. Bozic and Benizek [35] identified the profile and secondary losses of OFTs using numerical methods.

The OFT uses the transfer of kinetic energy from the water to the blade combined with the pressure difference produced by the draft tube [22]. The design of a OFT is based on the velocity triangle analysis, e.g. Necleba [36]. However, Nechleba's analysis has not been fully proven, as indicated by Othman et al. [37].

This study examines two problem areas that may be linked to the performance of the OFT: the Euler equation and the velocity triangle theory. Ho-Yan [24] has claimed that the Euler equation is not helpful when designing an OFT runner, because the equation only suggests that energy conversion is maximized by decreasing the axial velocity at the outlet side $\left(C_{x_{2}}\right)$, but does not recommend a method for accomplishing this. In addition, the velocity triangle theory does not account for losses. Moreover, the velocity triangle analysis becomes inaccurate in cases where the designer is unaware of changes in the velocity vector that may result from manufacturing defects. To provide recommendations for the design and manufacture of OFT runners to maximize the conversion of kinetic and potential energy, this study will analyzes the impact of gap size in two runners, called Runner A and Runner B; Runner A has five blades, while Runner B has six.

This study uses three methods to investigate the mismatches between expected and actual turbine power outputs. Analytical methods are used to design the turbine, and the method of experimentation is used to determine the actual performance of the turbine. Finally, a computational fluid dynamics (CFD) simulation is used to study the physical phenomena and re-check the velocity triangle of the turbine runner to detect possible mistakes in the design and manufacturing processes.

\section{METHODS AND MATERIALS}

\section{Turbine Runner Geometry}

The specific speed $\left(n_{s}\right)$ is the parameter most frequently used to determine which type of turbine should be used for certain conditions. The specific speed is the speed of a turbine that has geometry identical to the original turbine and is capable of producing unit power under the unit head [22]. The specific speeds of open flume or propeller turbines range from $300-1000 \mathrm{~m}-\mathrm{kW}$ [38]. Table 1 is used to determine the optimal number of blades $(z)$ and the optimal hub-to-tip ratio $\left(\frac{d_{h}}{D}\right)$ :

Table 1. Relationship between $n_{s}, \frac{d_{h}}{D}$, and $z$

\begin{tabular}{lcccccc}
\hline Specific speed $\left(\mathrm{n}_{\mathrm{s}}\right)$ & 1000 & 800 & 600 & 400 & 350 & 300 \\
\hline Hub-to-tip ratio $\left(\frac{\mathrm{d}_{\mathrm{h}}}{\mathrm{D}}\right)$ & 0.3 & 0.4 & 0.5 & 0.55 & 0.6 & 0.7 \\
Number of Blades $(z)$ & 3 & 4 & 5 & 6 & 8 & 10 \\
\hline
\end{tabular}


The blade is designed using the velocity triangle analysis to avoid uneven turbine rotation from hub to tip (see Figure 1).

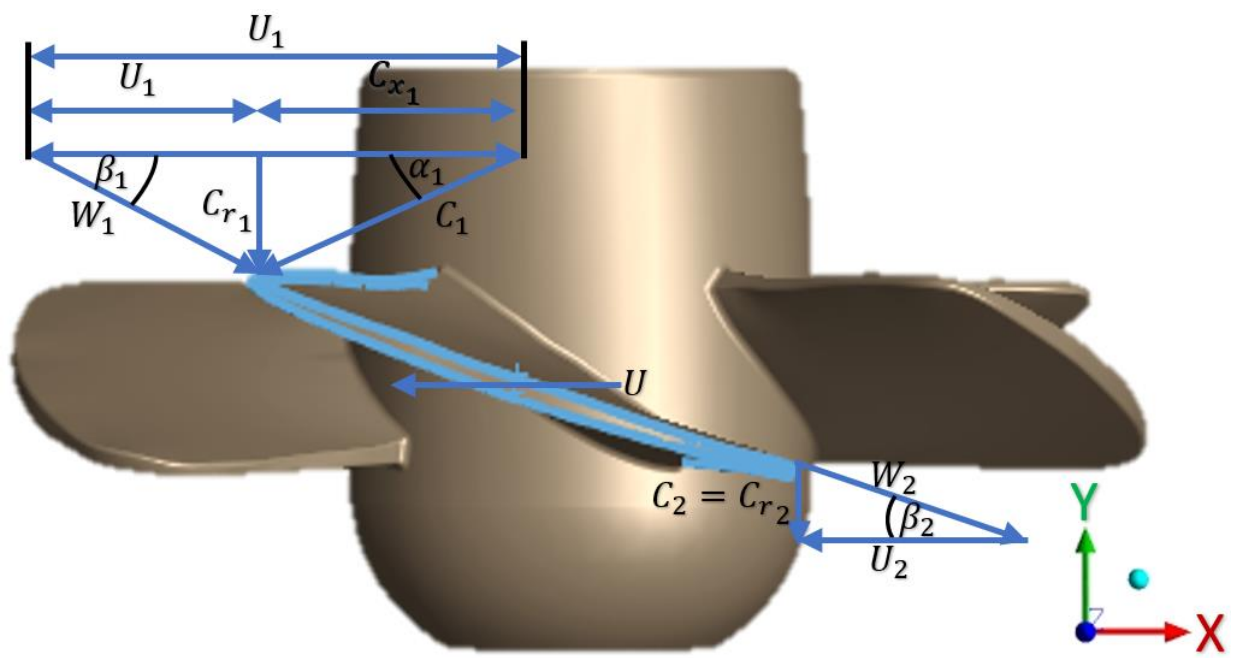

Figure 1. Velocity triangle analysis on OFT

In Figure $C$ is the absolute velocity, $W$ is the relative velocity, $U$ is the blade rotational velocity, the subscripts of $x$ and $r$ are the axial and the radial directions, $\omega$ is the rotational velocity, and $R$ is the radial of the runner. The OFT is categorized as an axial turbine.

To maintain the stability of the turbine rotation, the absolute velocity angle $(\alpha)$ and relative velocity angle $(\beta)$ at the inlet and outlet sides must be adjusted to blade rotational velocity $(U)$. After determining $\beta$ and $\alpha$ for each piece of the blade, the stagger angle $(\xi)$ should be defined, which is the angle between the chord line of the airfoil blade and the axial reference line [24].

In this study, the specific speed $\left(n_{s}\right)$ was chosen as equal to $469.25 \mathrm{~m}-\mathrm{kW}$. If this value is compared with the information in Table 1 , the recommended number of blades for this value is either five or six. Thus, this study uses two runner designs: five blades for Runner A and six blades for Runner B. Runner A uses a camber-twist blade design to facilitate the manufacturing process and its analysis. This is one of the advantages of Runner A compared to Runner B. However, it was predicted that Runner B would have a higher efficiency than Runner A, due to the predicted lift and drag forces of Runner B being higher than the forces of Runner A (since the shape of its blades use an airfoil concept). Consequently, Runner B manufacture will be more difficult than Runner A. Moreover, it will take longer to design Runner B than Runner A, as $\xi$ has to be analyzed first, so that the type and number of airfoils will have the optimal $F_{L}$ and $F_{D}$ at a predetermined $\beta$ angle.

The geometry of Runners $\mathrm{A}$ and $\mathrm{B}$ can be seen in Table 2 and 3 . The values $C_{x_{2}}, C_{r_{1}}$, and $\alpha_{1}\left(1.3 \mathrm{~m} / \mathrm{s}, 4.06 \mathrm{~m} / \mathrm{s}\right.$, and $64.44^{\circ}$, respectively) are constant along the blade of Runner $\mathrm{B}$, while for Runner A, only $C_{r_{1}}$ is constant (i.e., $4.06 \mathrm{~m} / \mathrm{s}$ ). 
Table 2. Dimensional velocity, angle, and NACA airfoil of Runner B

\begin{tabular}{cccccccc}
\hline \multirow{2}{*}{$d_{h} / D$} & $U$ & $C_{x_{1}}$ & $\alpha_{2}$ & $\beta_{1}$ & $\beta_{2}$ & $\alpha_{\text {aerofoil }}$ & $\begin{array}{c}\text { NACA } \\
\text { aerofoil }\end{array}$ \\
\cline { 2 - 6 } & $(\mathrm{m} / \mathrm{s})$ & $(\mathrm{m} / \mathrm{s})$ & $\left({ }^{\circ}\right)$ & $\left({ }^{\circ}\right)$ & $\left({ }^{\circ}\right)$ & & \\
\hline 1 & 9.73 & -1.15 & -67.08 & 17.86 & 14.02 & 1.92 & 6506 \\
0.9 & 8.76 & -1.42 & -62.38 & 20.02 & 14.95 & 2.54 & 6406 \\
0.8 & 7.79 & -1.76 & -57.05 & 22.74 & 15.89 & 3.42 & 6306 \\
0.7 & 6.81 & -2.2 & -51.01 & 26.25 & 16.78 & 4.73 & 4506 \\
0.6 & 5.84 & -2.78 & -44.32 & 30.92 & 17.5 & 6.71 & 4409 \\
0.5 & 4.87 & -3.6 & -37.05 & 37.32 & 17.8 & 9.76 & 4309 \\
0.4 & 3.89 & -4.82 & -29.39 & 46.36 & 17.32 & 14.52 & 2412 \\
\hline
\end{tabular}

Table 3. Dimensional angle and velocity of Runner A

\begin{tabular}{cccccc}
\hline \multirow{2}{*}{$d_{h} / D$} & $W$ & $U$ & $C_{x_{1}}$ & $\beta$ & $\alpha$ \\
\cline { 2 - 6 } & $(\mathrm{m} / \mathrm{s})$ & $(\mathrm{m} / \mathrm{s})$ & $(\mathrm{m} / \mathrm{s})$ & $\left(^{\circ}\right)$ & $\left(^{\circ}\right)$ \\
\hline 1.0 & 3.90 & 3.8 & -3.7 & 28.42 & 47.66 \\
0.7 & 4.01 & 5.3 & -3.3 & 25.38 & 50.89 \\
0.6 & 4.08 & 6.8 & -2.8 & 23.04 & 55.41 \\
0.5 & 4.15 & 8.2 & -2.5 & 20.62 & 58.38 \\
0.4 & 4.19 & 9.7 & -2.1 & 18.97 & 62.65 \\
\hline
\end{tabular}

Figures 2-a and Figure 2-b, respectively, are Runners A and B, based on Tables 2 and 3.

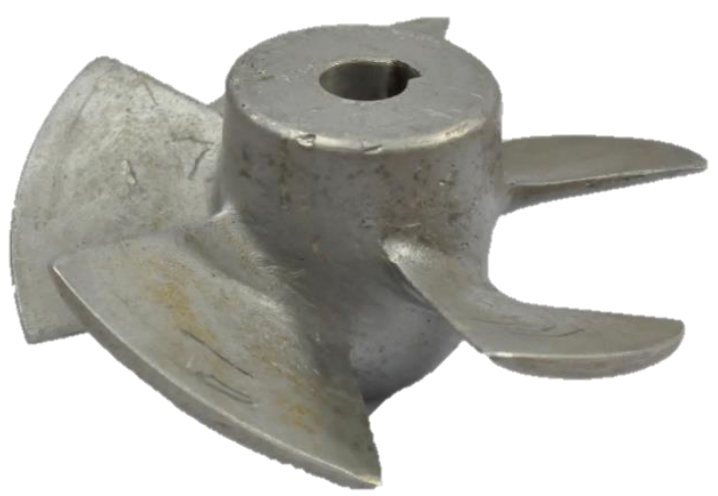

a) Runner $\mathrm{A}$

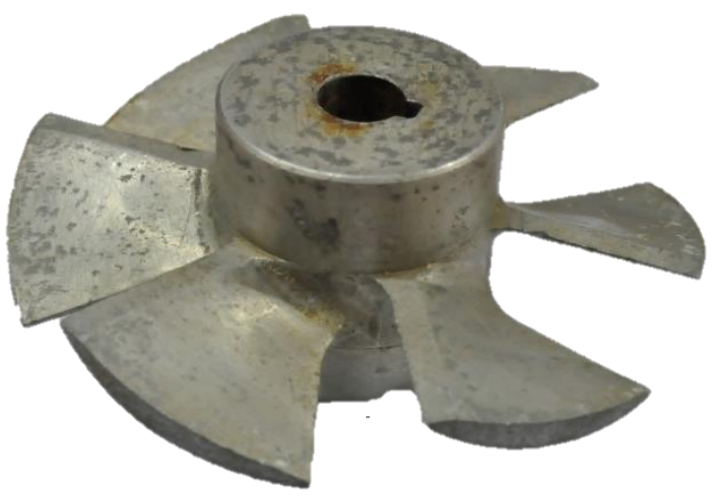

(b) Runner B

Figure 2. OFT runners

After all variables in Figure 1 have been defined, the torque $(\tau)$ analysis of the blade is received. The $\tau$ of each blade length is determined using Equations (1)-(3),

$$
\tau=\sum\left(F_{L_{i}} \cos \beta_{i}-F_{D_{i}} \cos \beta_{i}\right) r
$$


Where $F_{L_{i}}$ and $F_{D_{i}}$ are the coefficients of lift and drag, respectively.

The incoming flow to the blade is assumed to be shock-free; hence, $W_{1}$ has a direction that aligns with the angle $\beta_{1}$. If the absolute velocity vector $(C)$ on the outlet side has an axial direction that is parallel to the pivot axis, then $C_{2}=C_{r_{2}}$. Euler's equation for the OFT can then be written as (assumptions $U_{1}=U_{2}=U$ ):

$$
E=\frac{U\left(C_{x_{1}}-C_{x_{2}}\right)}{g}
$$

From Equation (2), it can be determined that performance will be optimized if the axial velocity on the outlet side is zero (i.e., $C_{x_{2}}=0$ ).

\section{Head Loss Analysis}

To maintain a close match between the mathematical predictions and the actual conditions, an analysis of head losses that occur in the piping system was conducted. In the OFT, these losses occur in the draft tube $\left(H_{f}\right)$ and penstock $\left(H_{L}\right)$ [39]. To analyze $H_{L}$, that occurs before the spiral volute, it was assumed that the channels are rectangular. The water passing through the channel before entering the turbine experiences head loss due to friction [39]. Because measurements are made at five locations along the channel prior to the turbine, the head loss analysis will be carried out for each channel segment, and the total channel loss $\left(H_{L}\right.$ total $)$, $H_{f}$, and $H_{L}$ are expressed, respectively, as

$$
\begin{gathered}
H_{f}=\frac{8 f L Q^{2}}{\pi^{2} g D^{5}} \\
H_{L_{i}}=\frac{f L_{i} Q_{i}^{2}\left(2 t_{i}+l_{i}\right)}{8 g t_{i}^{2} l_{i}^{3}} \\
H_{L \text { total }}=\sum_{i=1}^{5} H_{L_{i}}
\end{gathered}
$$

Where $f$ is the coefficient of iron friction, $t$ is the channel height, $l$ is the channel width, and $L$ is the distance of each measurement point (1.2 m) (see Figure 3).

\section{Output Power Analysis}

The power output is a function of torque $(\tau)$ and angular velocity $(\omega)$. The torque is a function of force $(F)$ and arm, which, in this case, is the radius of the turbine $\left(R_{\text {runner }}\right)$, if the force is considered to be applied at the blade tip. The angular velocity is derived from the rotational speed $(n)$. These relationships are expressed as $P_{\text {mech }}=\tau \times \omega$. Since the measured ones are force with unit of $\mathrm{N}$ and angular velocity with unit of rpm, which must be converted to $\mathrm{N} \cdot \mathrm{m}$ and $\mathrm{rad} / \mathrm{s}$, then

$$
P_{\text {mech }}=F \times R_{\text {runner }} \times \frac{2 \times \pi \times N}{60}
$$

The power generated $\left(P_{g e n}\right)$ is a function of voltage $(E)$ and current $(I)$ [38]: 


$$
P_{g e n}=E \times I
$$

Where $E$ is voltage (V) and $I$ is current (A).

\section{Experimental Method}

Experiments were conducted to validate the mathematical analysis used in this study. Four variables were measured: water discharge, torque, turbine rotational speed, and power output (in terms of its voltage and current). The tests were conducted in a laboratory with an available water head of $2.71 \mathrm{~m}$; the runner and hub diameters were $0.124 \mathrm{~m}$ and $0.05 \mathrm{~m}$, respectively. Two runners were compared: Runner A, with five blades, and B, with six. The inlet and outlet angle of attack of Runner B were greater than those of Runner A. The generator specifications include four poles with three phases and a maximum rotational speed of $1500 \mathrm{rpm}$.

The schematic diagram of the turbine system is shown in Figure 3. The measurement of discharge was done manually at five points, each point is $1.2 \mathrm{~m}$ : measure of water height to determine the cross-sectional flow area of water and flow velocity using a $0.03 \mathrm{~m}$ diameter of cork (fishing cork). This measurement approach was used to minimize errors. The angular velocity of the turbine was measured using a tachometer DT-6236B with an accuracy of $0.05 \%$, and the torque load was measured using a cell with an accuracy of $0.02 \%$ that was connected to the data acquisition unit. Multimeters were used to measure AC voltage and current with accuracies of $1.2 \%$ and $2 \%$, respectively.

To minimize the effects of measurement errors, statistical analyses were conducted on the data obtained. Before the data could be analysed, data filtering was done using Chauvenet's criteria. The five stages of the analysis and data interpretation were: determination of the average value of the sample, estimation of the standard deviation, determination of the default error value, estimation of the total uncertainty and that of each variable.

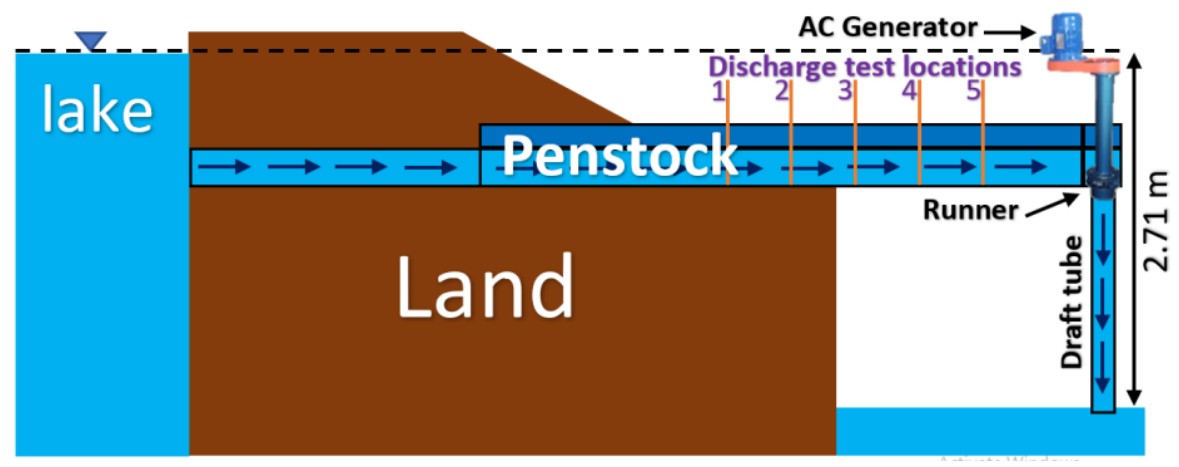

Figure 3. Schematic of OFT

\section{CFD Simulations}

This study used ANSYS Fluent 15.0 to perform CFD simulations because this software can be considered as a powerful tool to describe the hydraulics of reaction turbines $[17,40]$. The CFD simulations were used to verify the results of the velocity triangle analysis of the OFT. Simulations were performed in steady state. 
The following boundary conditions were specified as a flow rate of $0.041 \mathrm{~m}^{3} / \mathrm{s}$ at the inlet, and a specified pressure at the outlet equal to zero or atmospheric pressure. The solver type was pressure-based (because the fluid was incompressible) [41], gravity was $9.81 \mathrm{~m} / \mathrm{s}^{2}$, and the $k-\varepsilon$ standard turbulence model was used to predict the turbulent flow [29]. Based on reports, this model is accurate enough to predict the flow field that occurs in propeller turbines [18]. Interpolation method was used is COUPLE. Equation (8) for $k$ (kinetic energy) is as follows:

$$
\frac{D k}{D t}=\frac{\partial}{\partial x_{i}}\left[\frac{\mu_{e f f}}{\sigma_{k}} \frac{\partial k}{\partial x_{i}}\right]+\left[\mu_{t}\left(\frac{\partial U_{i}}{\partial x_{j}}+\frac{\partial U_{j}}{\partial x_{i}}\right)-\frac{2}{3} \rho \delta_{i j} k\right] \frac{\partial U_{j}}{\partial x_{i}}-c_{D} \frac{\rho k^{3 / 2}}{l_{m}}
$$

Equation (9) for $\varepsilon$ (dissipation rate) is the following:

$$
\frac{D \varepsilon}{D t}=\frac{\partial}{\partial x_{i}}\left[\frac{\mu_{e f f}}{\sigma_{\varepsilon}} \frac{\partial \varepsilon}{\partial x_{i}}\right]+c_{\varepsilon, 1}\left[\mu_{t}\left(\frac{\partial U_{i}}{\partial x_{j}}+\frac{\partial U_{j}}{\partial x_{i}}\right)-\frac{2}{3} \rho \delta_{i j} k\right] \frac{\partial U_{j}}{\partial x_{i}}-c_{\varepsilon, 1} \frac{\rho \varepsilon^{2}}{k}
$$

To minimize errors in the numerical results, a test for mesh independence was conducted with three different mesh sizes: coarse (457332 elements), medium (1033956 elements), and fine (1834786 elements). Due to the complex shape of the runners, with curved geometry and acute angles, a tetrahedral mesh was used (Figure 4).

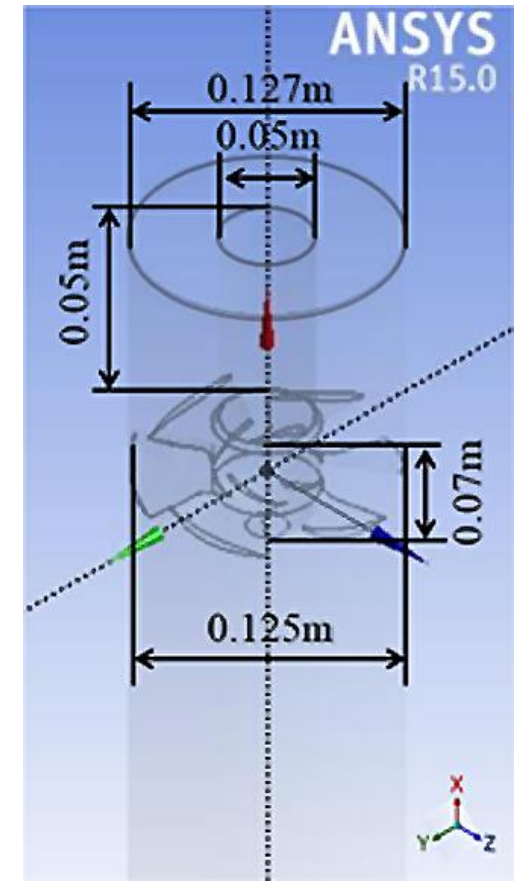

(a) Geometry setup

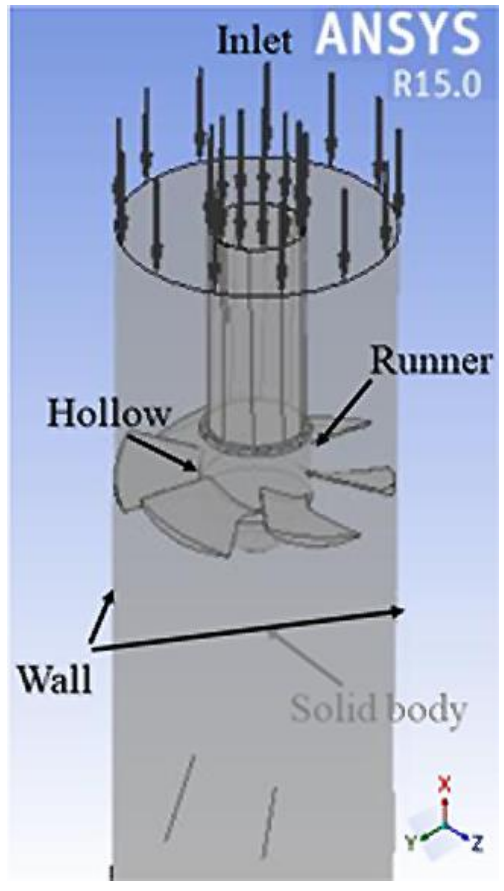

(b) Boundary condition setup 


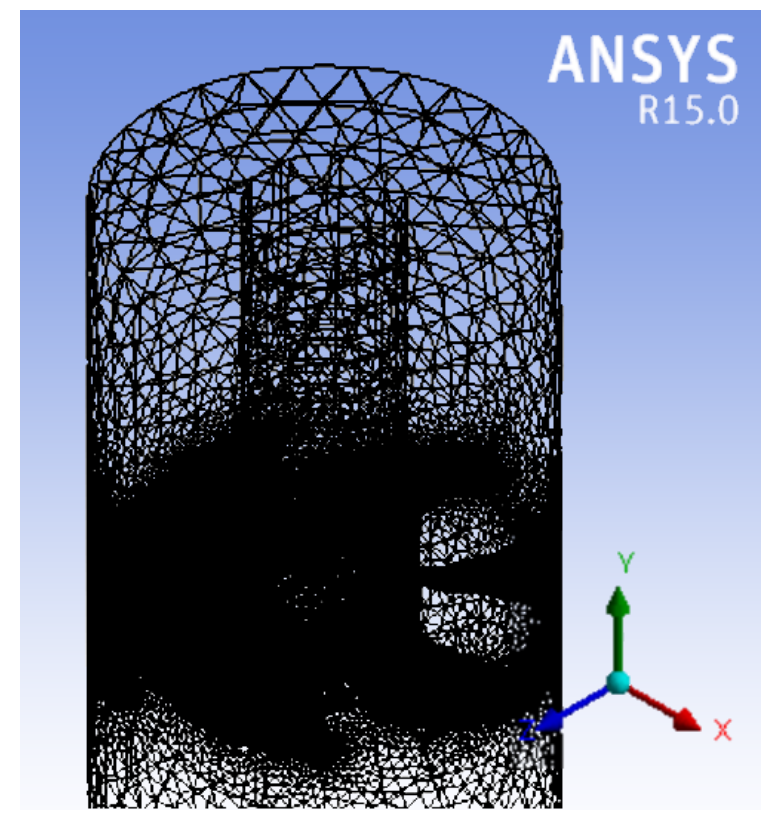

(c) Meshing process

Figure 4. CFD simulation setup

Mesh independency was determined by comparing the torque $(\tau)$ of Runner B to the torque obtained from simulations. In addition, a Grid Convergence Index (GCI) analysis was performed to determine the percentage of error between the pairs of mesh sizes (i.e., fine to medium, and medium to coarse) [42]; the GCI for fine to medium mesh is

$$
\mathrm{GCI}_{12}=F_{S} \times\left|\frac{1}{\tau_{\text {fine }}} \frac{\tau_{\text {medium }}-\tau_{\text {fine }}}{r_{12} p_{n}-1}\right| \times 100 \%
$$

where $F_{s}$, a safety factor, was assigned the value of 1.25 . Prior to this analysis, the analysis of the order of convergence observed $\left(p_{n}\right)$ was conducted using Equation (11). In addition, Richardson's extrapolation $\left(P r_{h=0}\right)$ or exact value was applied to the two best mesh sizes (fine to medium mesh category) to obtain an approximate value of the velocity recovery at a zero-grid distance using Equation (13) [42],

$$
\begin{gathered}
p_{n+1}=\ln \left[\left(\frac{\tau_{\text {coarse }}-\tau_{\text {medium }}}{\tau_{\text {medium }}-\tau_{\text {fine }}}\left(r_{12} p_{n}-1\right)\right)+r_{12} p_{n}\right] / \ln \left(r_{12} \cdot r_{23}\right) \\
P r_{h=0}=\tau_{\text {fine }}-\left(\frac{\tau_{\text {medium }}-\tau_{\text {fine }}}{r_{12} p_{n+1}-1}\right) \\
r_{12}=\left(\frac{M_{\text {medium }}}{M_{\text {fine }}}\right)^{0.5}
\end{gathered}
$$

where $r_{12}$ is the grid refinement ratio and $M$ is the mesh number. 


\section{RESULTS AND DISCUSSION}

\section{Analytical Results}

The airfoil geometry of the blades was used to improve the angular velocity and the torque of the turbine. Therefore, the determination of the airfoil type based on the ratio of the lift and the drag forces is highest with the airfoil attack angle $\left(\alpha_{\text {aerofoil }}\right)$. To obtain a stable angular velocity, the value of the lift and drag coefficients should increase towards the blade tip. Table 4 summarizes the analysis using the stagger angle $(\xi)$ and Equation (1) for Runner $\mathrm{B}$, while Table 5 summarizes the analysis of Runner A using the lift $\left(F_{L_{i}}\right)$ and drag $\left(F_{D_{i}}\right)$ coefficients with Equation (1).

Table 4. Analysis of $\xi, C_{L}, C_{D}, F_{L}, F_{D}$, and $\tau$ on blade Runner B

\begin{tabular}{|c|c|c|c|c|c|c|}
\hline$d_{h}$ & $\xi$ & $C_{I}$ & $C_{D}$ & $F_{L}$ & $F_{D}$ & $\tau$ \\
\hline$/ D$ & $\left({ }^{\circ}\right)$ & $\mathrm{c}_{L}$ & ${ }^{C_{D}}$ & $(\mathrm{~N})$ & $(\mathrm{N})$ & $(\mathrm{N} \cdot \mathrm{m})$ \\
\hline 1 & 15.94 & 0.6 & 0.03 & 15.42 & 0.77 & 0.9 \\
\hline 0.9 & 17.49 & 0.6 & 0.03 & 15.3 & 0.76 & 0.87 \\
\hline 0.8 & 19.32 & 0.6 & 0.03 & 15.13 & 0.76 & 0.85 \\
\hline 0.7 & 21.52 & 0.7 & 0.035 & 17.41 & 0.87 & 0.94 \\
\hline 0.6 & 24.21 & 0.7 & 0.04 & 17.06 & 0.98 & 0.88 \\
\hline 0.5 & 27.56 & 1 & 0.07 & 23.7 & 1.66 & 1.11 \\
\hline 0.4 & 31.84 & 1.2 & 0.1 & 27.25 & 2.27 & 1.06 \\
\hline
\end{tabular}

Table 5. Analysis of $C_{L}, C_{D}, F_{L}, F_{D}$, and $\tau$ on blade Runner A

\begin{tabular}{cccccc}
\hline$d_{h}$ & \multirow{2}{*}{$C_{L}$} & \multirow{2}{*}{$C_{D}$} & $F_{L}$ & $F_{D}$ & $\tau$ \\
\cline { 4 - 6 }$/ D$ & & & $(\mathrm{~N})$ & $(\mathrm{N})$ & $(\mathrm{N} \cdot \mathrm{m})$ \\
\hline 1 & 0.84 & 0.45 & 13.31 & 6.66 & 0.190 \\
0.7 & 0.77 & 0.37 & 18.78 & 8.91 & 0.408 \\
0.6 & 0.72 & 0.31 & 26.09 & 11.10 & 0.732 \\
0.5 & 0.66 & 0.25 & 33.62 & 12.65 & 1.172 \\
0.4 & 0.61 & 0.21 & 65.34 & 22.46 & 3.378 \\
\hline
\end{tabular}

For the analysis of losses in the draft tube using Equation (3), the coefficient of friction $(f)$ for PVC pipes was determined from the Moody diagram as 0.0014 . Then, the energy losses on the channel (penstock) were analyzed using Equation (4) and (5). For a steel penstock, the coefficient of friction is 0.6 ; the effective head $\left(H_{e f f}\right)$ is a function of the available head, minus losses, and because the loss value is known, the $H_{\text {eff }}$ can be known. Table 6 summarizes the analysis losses that occur. 
Table 6. Analysis of $H_{f}, H_{L, t o t a l}$, and $H_{e f f}$

\begin{tabular}{lc}
\hline \multicolumn{1}{c}{ Description } & Value \\
\hline Losses in the draft tube $\left(H_{f}\right)(\mathrm{m})$ & 0.01 \\
Total of losses in the penstock $\left(H_{\text {L total }}\right)(\mathrm{m})$ & 0.0277 \\
Effective head $\left(H_{\text {eff }}\right)(\mathrm{m})$ & 2.66 \\
\hline
\end{tabular}

Thus, the available power is $1176.93 \mathrm{~W}$.

\section{Experiment Results}

The measured discharge at the five locations had different water levels. The water level increased towards the turbine, which caused the cross-sectional flow area to increase, but caused the water velocity to the turbine to decrease due to the conservation of mass (i.e., $m_{1}=m_{2}$ ). The measurement of the cross-sectional area and the velocity of the water is represented in Figure 5. To find out the available discharge must use the average flow velocity of water while the measured is the maximum velocity. The average water flow velocity is $85 \%$ of the maximum [38]. Based on Figure 5, the average discharge as $0.045 \pm$ $0.0055 \mathrm{~m}^{3} / \mathrm{s}$.

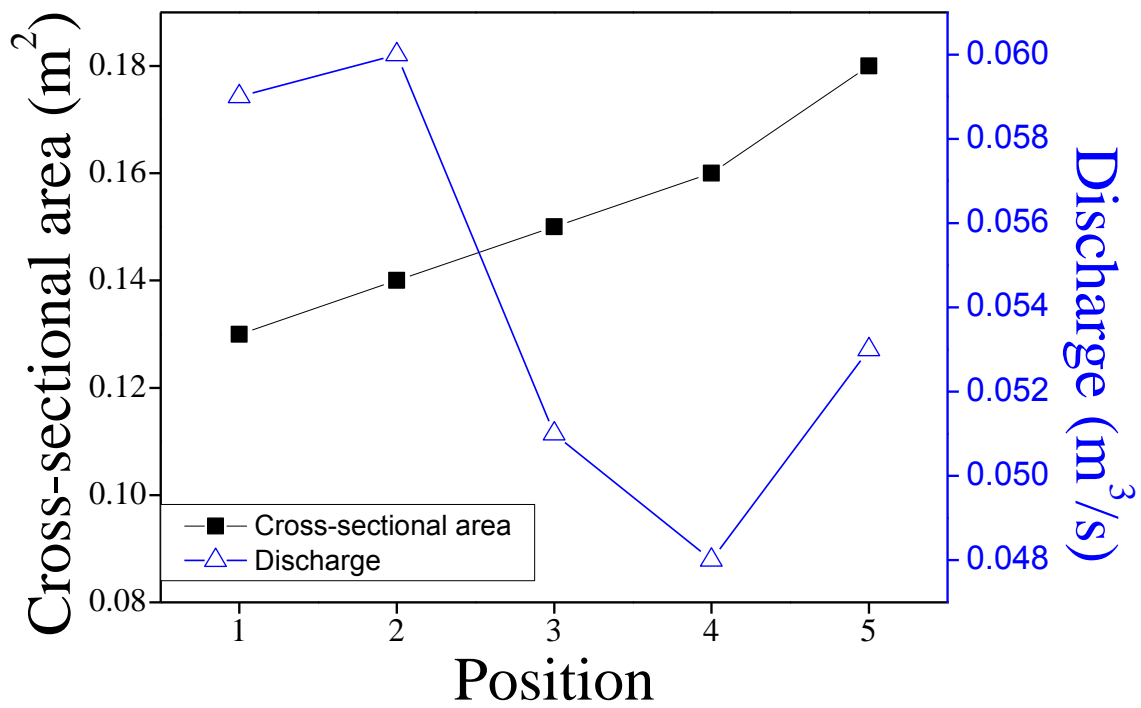

Figure 5. Graph of the cross-sectional area and the water velocity

The theoretical analysis was conducted testing the runners at $1500 \mathrm{rpm}$ (maximum speed of the generator), while results of CFD simulations refer to $800 \mathrm{rpm}$ (see Table 7). This difference is allegedly because the theoretical does not calculate losses in more detail than computational. The measurements indicated that the rotational speed of Runner B was 3338 $\pm 16.98 \mathrm{rpm}$, and the rotational speed of Runner A was $2732.08 \pm 13.78 \mathrm{rpm}$. However, Runner A produced a higher torque than Runner B $(3.25 \pm 0.018 \mathrm{~N} \cdot \mathrm{m}$ versus $2.49 \pm 0.016$ $\mathrm{N} \cdot \mathrm{m}$, respectively). Furthermore, the electrical power $\left(P_{\text {elec }}\right)$ of Runner A was $550 \pm 17.6 \mathrm{~W}$ 
and Runner B was $499.27 \pm 15.97$, respectively. The Runner A produced a higher electrical power $\left(P_{\text {elec }}\right)$ than Runner B. Thus, the power generated by Runner B was not as significant as the power generated by Runner A; Table 7 summarizes the calculations and mechanical power while Table 8 presents the measurements of electrical power. The electrical power has been measured to ensure that the water power conversion by Runner $A$ is higher than the conversion by B.

Table 7. Performance of Runners A and B based on analytical, computational and experimentation results

\begin{tabular}{ccccccc}
\hline & \multicolumn{6}{c}{ Descriptions } \\
\cline { 2 - 7 } Parameter & \multicolumn{2}{c}{ Analytical } & \multicolumn{2}{c}{ Computational } & \multicolumn{2}{c}{ Experiment } \\
\cline { 2 - 7 } & $\mathrm{A}$ & $\mathrm{B}$ & $\mathrm{A}$ & $\mathrm{B}$ & $\mathrm{A}$ & $\mathrm{B}$ \\
\hline$\tau(\mathrm{N} \cdot \mathrm{m})$ & 5.88 & 6.61 & 9.93 & 9.12 & 3.25 & 2.59 \\
$n(\mathrm{rpm})$ & 1500 & 1500 & 800 & 700 & 2732.08 & 3338 \\
$P_{\text {mech }}(\mathrm{W})$ & 923.59 & 1038.30 & 831.89 & 668.53 & 929.83 & 905.35 \\
$\eta_{\text {mech }}(\%)$ & 76.64 & 86.15 & 69.03 & 55.5 & 79.18 & 77.09 \\
\hline
\end{tabular}

Table 8. Electrical power and efficiency measurement of Runners A and B

\begin{tabular}{ccc}
\hline Parameter & Runner A & Runner B \\
\hline$I(\mathrm{~A})$ & $2.5 \pm 0.05$ & $2.426 \pm 0.05$ \\
$E(\mathrm{~V})$ & $220 \pm 2.47$ & $205.8 \pm 2.64$ \\
$P_{\text {elec }}(\mathrm{W})$ & $550 \pm 17.6$ & $499.27 \pm 15.97$ \\
$\mathrm{\eta}_{\text {gen }}(\%)$ & 95 & 95 \\
$\mathrm{\eta}_{\text {total }}(\%)$ & 46.73 & 42.42 \\
\hline
\end{tabular}

\section{Numerical Results}

Before running the required simulations, $\mathrm{GCI}$ analysis is needed to determine the optimum mesh number (independency test). The independency test for the mesh number was carried out using Runner B. Validation or independency test is not referenced using experimental results. This is because the computation has its own value or magnitude where the value must be tested for accuracy (error) based on the results themselves [43,44]. From the numerical results, the torque produced by Runner B was $2.03,2.45$, and $2.55 \mathrm{~N} \cdot \mathrm{m}$ for the coarse, medium, and fine meshes, respectively (Table 9). Using these results, GCI analysis was then carried out. Before iterations of to find a $p_{h}$ value using Equation (11), the value of $r$ first had to be determined using Equation (13). Further, using Equation (12), the Richardson extrapolation $\left(\operatorname{Pr}_{h=0}\right)$ or called exact value. Using Equation (11), the $\mathrm{GCI}_{12}$ or error simulation using a mesh number fine category can be determined. Summary of all analysis of GCI in Table 9. 
Table 9. Water flow velocity with varying grid spacing

\begin{tabular}{cccccc}
\hline Mesh Number & $\begin{array}{c}\text { Normalized } \\
\text { spacing }\end{array}$ & $\begin{array}{c}\tau \\
(\mathrm{N} \cdot \mathrm{m})\end{array}$ & $r$ & $p$ & GCI \\
\hline 457332 & 2 & 2.03 & - & - & - \\
1033956 & 1.33 & 2.45 & 1.50 & - & - \\
1834786 & 1 & 2.55 & 1.33 & 3.026 & $3.55 \%$ \\
\hline
\end{tabular}

These results indicate that the fine mesh was in the asymptotic range which generally the percentage limit for computing errors is les than $5 \%$ while the mesh size error generated was only $3.55 \%$. Thus, based on the results of GCI the fine mesh number category can be said not to be influenced by the number of mesh so that this mesh number has been verified and is valid for use. In addition, the numerical results summarized in Figure 6 are verified by their similarity to those obtained from studies by Simpson and Williamson [29], in which the generated torque decreased as the rotational speed increased.

The torque generated by Runner $\mathrm{A}$ is higher than that of Runner $\mathrm{B}$ at the same rotational speeds; furthermore, with a discharge of $0.041 \mathrm{~m}^{3} / \mathrm{s}$ and a head of $2.71 \mathrm{~m}$, the simulation results show that the highest efficiency for Runner A is $69.03 \%$ at $800 \mathrm{rpm}$ and with a torque of $9.93 \mathrm{~N} \cdot \mathrm{m}$, whereas these values for Runner B are 55.5\%, $700 \mathrm{rpm}$, and 9.12 $\mathrm{N} \cdot \mathrm{m}$, respectively (Figure 6).

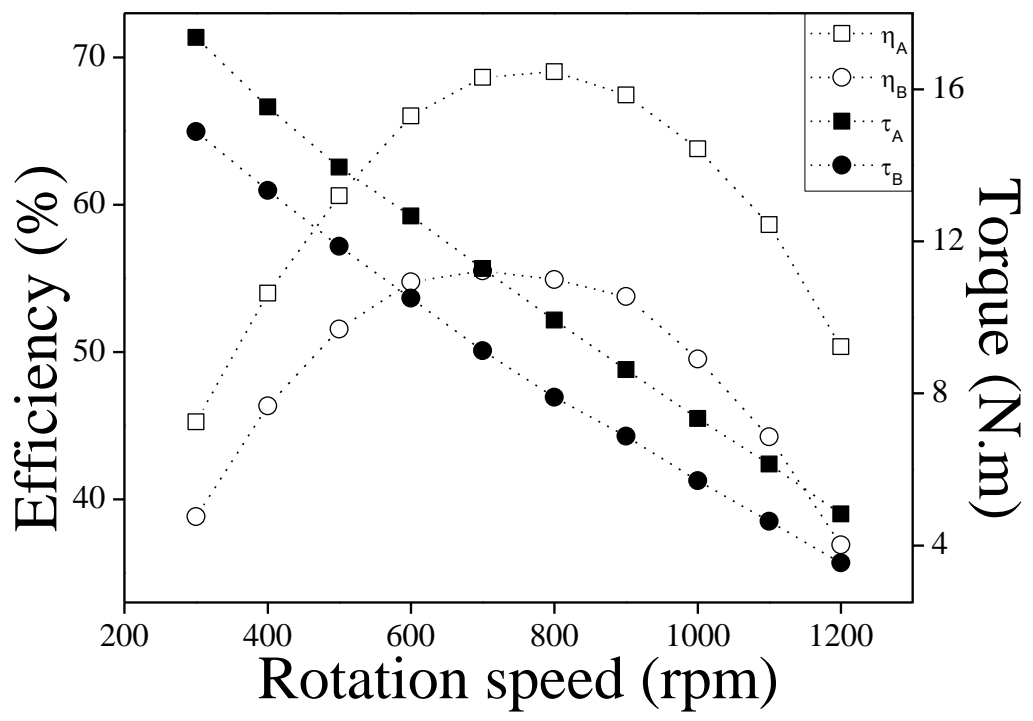

Figure 6. Efficiency and torque versus rotation speed based on numerical results

\section{Discussion}

Runner B perhaps produces less power because of the gaps between its blades (Figure 7, where the blue area indicates losses due to the gaps between the blades); thus, Runner B captures less energy from the water. In addition, the higher number of blades in Runner B greater flow loss. 


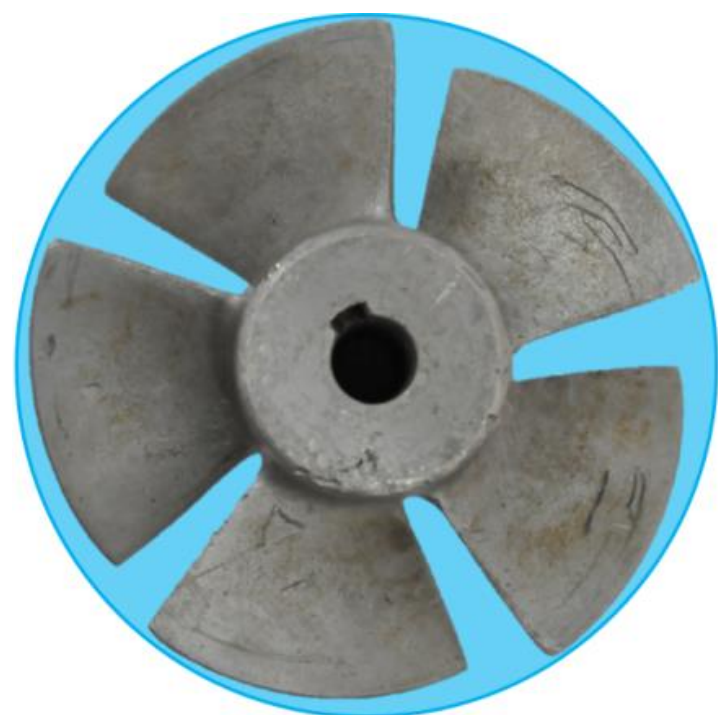

(a) Runner A

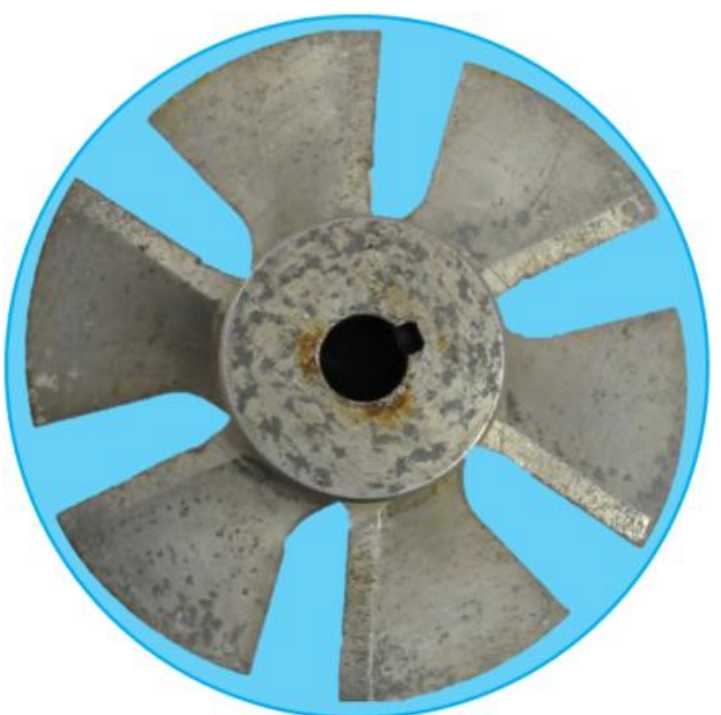

(b) Runner B

Figure 7. Losses due to gaps between blades

Considering the mathematical analysis, Runner B has the same radial velocity as Runner A (see Tables 2 and 3). However, because of the higher losses in Runner B (due to the larger gaps between the blades), the radial velocity increases at the outlet. Since the absolute velocity at the inlet $\left(C_{1}\right)$ does not hit the blade, the radial velocity at the outlet is almost equal to that at the inlet (i.e. $C_{r_{2}} \approx C_{r_{1}}$ ). Thus, the absolute velocity vector at the outlet changes direction, such that the absolute velocity at the outlet $\left(C_{2}\right)$ is not equal to the absolute radial velocity (i.e. $C_{2} \neq C_{r_{2}}$ ), which results in a non-zero value of $C_{x_{2}}$. On the other hand, the runner velocity $(U)$ increases because

$$
\begin{gathered}
C_{2}{ }^{\prime}=C_{r_{2}}{ }^{\prime}+C_{x_{2}} \\
U_{2}{ }^{\prime}=U_{2}+C_{x_{2}}
\end{gathered}
$$

Thus, $U_{1}=U \neq U_{2}$, because $U_{2}$ becomes $U_{2}{ }^{\prime}$, and the value $U$ is expressed as

$$
U=\frac{U_{2}{ }^{\prime}+U_{1}}{2}
$$

The next impact is that the turbine rotation becomes unbalanced, which causes vibration, as $U_{1}=U \neq U_{2}$. In addition, Runner B potentially experiences cavitation, because the critical value of cavitation is a function of the velocity vector at the outlet of the runner. Cavitation occurs if the water pressure after the runner is smaller than the saturated vapor pressure [22]. On close observation, cavitation occurs mostly at the tip of the runner blade, as shown in Figure 9-b, presumably because the fast-moving blades of the turbine so that the local dynamics head increases due to the action of the blade and causes the static pressure to fall (and increases the absolute velocity). Consequently, the increased absolute velocity will decrease the absolute pressure, where the absolute pressure at the outlet (draft tube) drops below the saturated water vapor pressure at that water temperature. Figure 8 shows the velocity triangle analysis of the radial velocity at the outlet of the Runner B. 


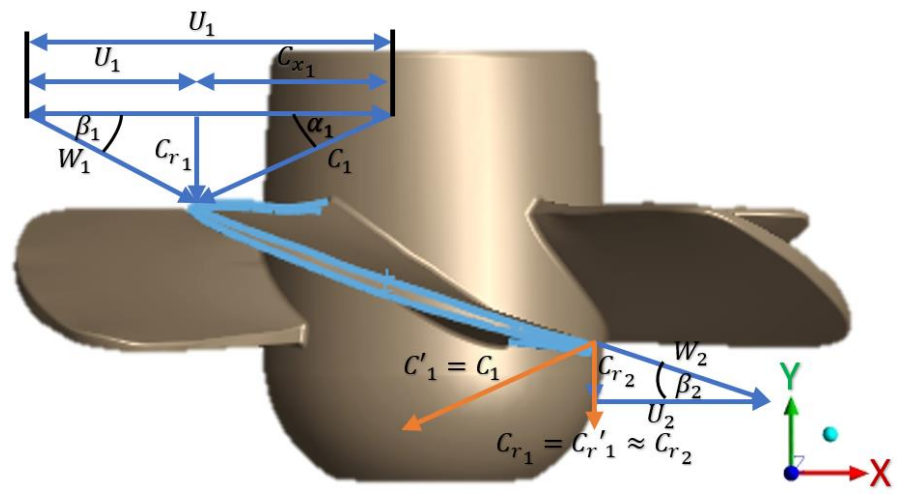

Figure 8. Velocity triangle analysis at the outlet of Runner B

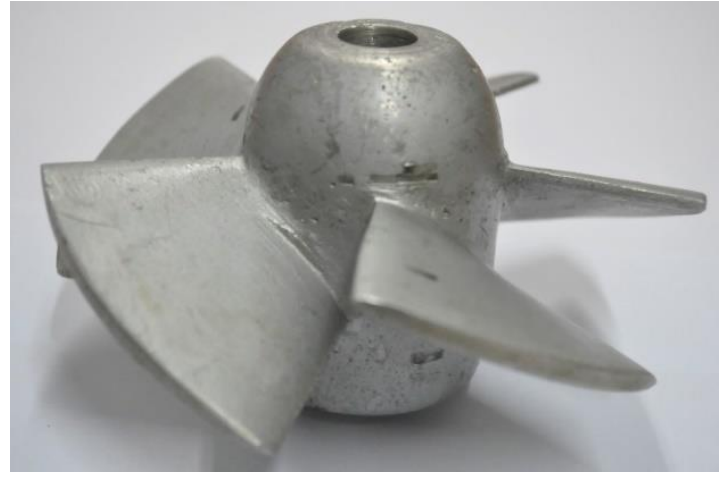

(a) Runner A

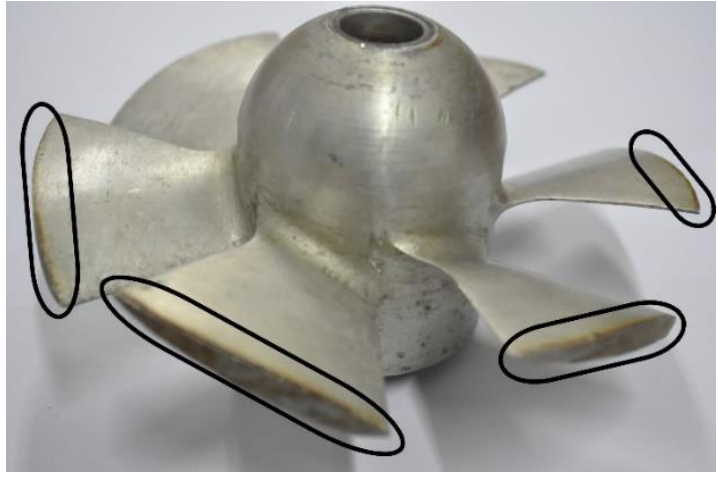

(b) Runner B

Figure 9. Cavitation symptoms on runner blade tips

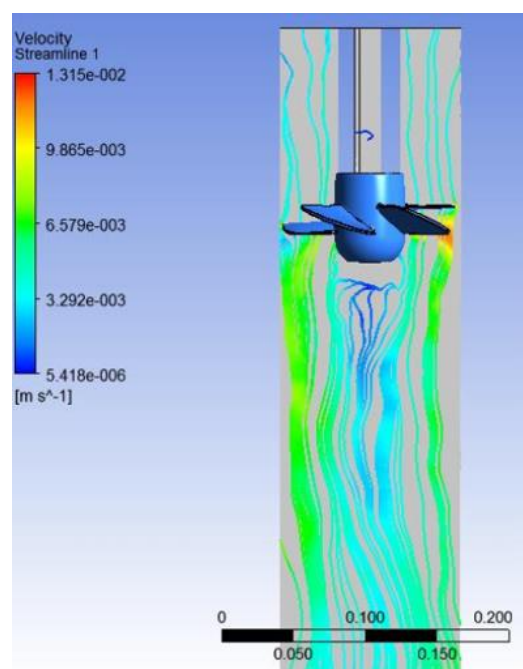

(a) Runner A

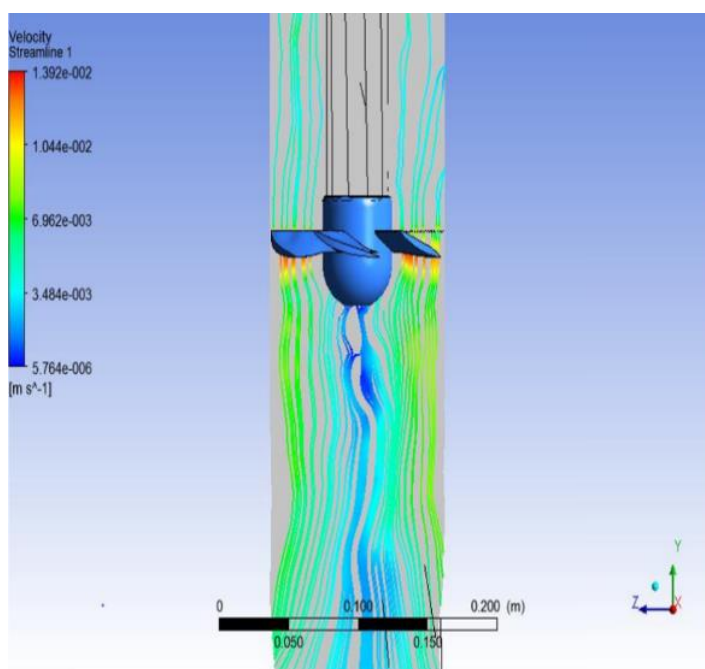

(b) Runner B

Figure 10. Streamline visualization at $1200 \mathrm{rpm}$ rotational speed 
The effect of increasing the absolute velocity vector at the outlet (after the water passes through the runner) is verified using the results of the numerical simulations. Figure 10 shows the streamlines and vortex flows formed after the water passed through the blades of Runners A and B. The velocity triangle theory, as illustrated in Figure 1 for Runner A and Figure 8 for Runner B, is equivalent to the numerical results shown in Figure 10-a and Figure 10-b, respectively. For Runner A, the swirling flow of water that occurs after passing the turbine is needed to minimize the radial velocity at the outlet so that the lost kinetic energy into potential energy becomes torque. However, the vortex flow that occurs on the blade should be avoided to prevent cavitation. In addition, based on Figure 6, the numerical results indicate that Runner B achieves a lower efficiency than that of Runner A because the resulting torque is lower, which also means that the potential energy of the water is not fully captured by Runner B.

The visualization of the pressure contours that occur in the draft tube also shows that the pressure gradient across Runner A is steeper than the pressure gradient across Runner B (Figure 11). Presumably, this is because the swirling flow after passing through Runner A lowers the relative velocity in the draft tube in accordance with the law of the conservation of energy (Bernoulli's principle). Based on Bernoulli's principle, an increase in the speed of a fluid occurs simultaneously with a decrease in pressure or a decrease in the fluid potential energy, hence conserving energy. Thus, the draft tube on Runner A functions properly to minimize the loss of kinetic energy of the water by converting it into potential energy or pressure [45].

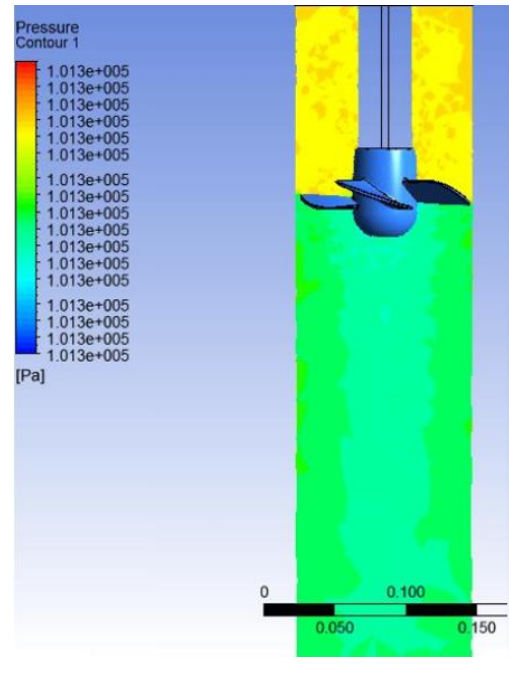

(a) Runner A

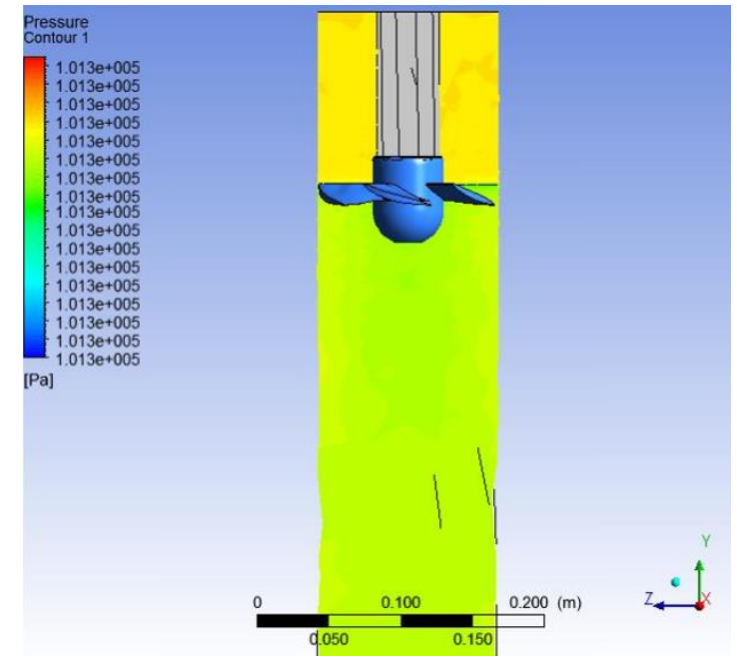

(b) Runner B

Figure 11. Visualization of pressure contours in draft tube at $1200 \mathrm{rpm}$

A study by Othman et al. obtained similar results using numerical methods [37]. Othman et al. described how the number of blades affects the power produced by the turbine [37]. The power produced by an OFT is inversely proportional to the number of blades [37]. Unlike the results presented in this paper, the results of Othman et al. [37] were not verified by experimental methods. Ramos et al. [46] also explained that the greater the number of 
blades, the less power will be generated. Runner A, with more blades, produces high angular velocity but little torque [46]. Results obtained from previous studies using numerical methods have indicated that runners with five blades achieved less efficiency than those with six blades [23]. These studies claim that the higher losses were due to the bigger gaps of the five-blade runner compared to those of the six-blade runner.

\section{CONCLUSION}

Based on the results, there are two conditions are required to maximize turbine performance. First, swirling flow after the runner. Swirling flow is required after the water passes the runner because swirling flow minimizes the radial velocity at the outlet, so that the draft tube can function properly (the pressure on the draft tube decreases). The theoretical assumption of free vortex flow when water is in the runner blade is used to simplify the design. The thing should be avoided is the occurrence of swirling of vortex flow in the runner blade causes the blade wall to peel off, thereby shortening the service life of the turbine. Vortex flow can be avoided by designing the turbine blade with a relative velocity angle $(\beta)$ that is large enough to delay flow separation at the blade. Second, minimizing gaps between the runner blades. The errors between the mathematical calculations and the actual conditions are predominantly due to the gap between the blades changing the velocity vector at the outlet side unbalances the angular velocity of the runner and decreases the absorbed torque because the draft tube does not function optimally (the velocity increases, then the pressure decreases). Another consequence is the cavitation in the runner when the pressure at the outlet approaches the value of the saturated water vapor pressure at that water temperature if there is a gap between blades. For maximizing the turbine performance is to carefully choose the dimensions of the blade to avoid large gaps between the blades (when the gap size approaches zero, analysis results approach the actual conditions).

A future study will examine whether a swirling vortex contributes to the energy transfer in an OFT. This is because one way to minimize the tangential velocity of water at the outlet $\left(C_{x_{2}}\right)$ is to reduce the relative velocity angle $\left(\beta_{2}\right)$, which promotes the swirling flow of water after it passes through the runner.

\section{ACKNOWLEDGEMENT}

The authors would like to thank to Dr. Emanuele Quaranta of Politecnico di Torino for his suggest and input in writing this paper and the Directorate of Research and Community Service (DRPM) Universitas Indonesia as a funder, with grant no. 1343/UN2.R3.1/HKP.05.00/2018. 


\section{REFERENCES}

[1] Hasan MH, Muzammil WK, Mahlia TMI, Jannifar A, Hasanuddin I. A review on the pattern of electricity generation and emission in Indonesia from 1987 to 2009. Renewable and Sustainable Energy Reviews 2012;16:3206-19.

[2] Hasan MH, Mahlia TMI, Nur H. A review on energy scenario and sustainable energy in Indonesia. Renewable and Sustainable Energy Reviews 2012;16:2316-28.

[3] Alhamid MI, Daud Y, Surachman A, Sugiyono A, Aditya HB, Mahlia TMI. Potential of geothermal energy for electricity generation in Indonesia: A review. Renewable and Sustainable Energy Reviews 2016;53:733-40.

[4] Mahlia TMI, Abdulmuin MZ, Alamsyah TMI, Mukhlishien D. An alternative energy source from palm wastes industry for Malaysia and Indonesia. Energy Conversion and Management 2001;42:2109-18.

[5] Kusumo F, Silitonga AS, Masjuki HH, Ong HC, Siswantoro J, Mahlia TMI. Optimization of transesterification process for Ceiba pentandra oil: A comparative study between kernel-based extreme learning machine and artificial neural networks. Energy 2017;134:24-34.

[6] Kusumo F, Silitonga AS, Ong HC, Masjuki HH, Mahlia TMI. A comparative study of ultrasound and infrared transesterification of Sterculia foetida oil for biodiesel production. Energy Sources, Part A: Recovery, Utilization, and Environmental Effects 2017;39:1339-46.

[7] Jayed MH, Masjuki HH, Kalam MA, Mahlia TMI, Husnawan M, Liaquat AM. Prospects of dedicated biodiesel engine vehicles in Malaysia and Indonesia. Renewable and Sustainable Energy Reviews 2011;15:220-35.

[8] Silitonga AS, Atabani AE, Mahlia TMI, Masjuki HH, Badruddin IA, Mekhilef S. A review on prospect of Jatropha curcas for biodiesel in Indonesia. Renewable and Sustainable Energy Reviews 2011;15:3733-56.

[9] Aditiya HB, Chong WT, Mahlia TMI, Sebayang AH, Berawi MA, Nur H. Second generation bioethanol potential from selected Malaysia's biodiversity biomasses: A review. Waste Management 2016;47:46-61. doi:https://doi.org/10.1016/j.wasman.2015.07.031.

[10] Aditiya HB, Mahlia TMI, Chong WT, Nur H, Sebayang AH. Second generation bioethanol production: A critical review. Renewable and Sustainable Energy Reviews 2016;66:631-53.

[11] Hossain N, Zaini JH, Mahlia TM. A Review of Bioethanol Production from Plantbased Waste Biomass by Yeast Fermentation. Int J Technol 2017;8:5-18.

[12] Aditya L, Mahlia TMI, Rismanchi B, Ng HM, Hasan MH, Metselaar HSC, et al. A review on insulation materials for energy conservation in buildings. Renewable and Sustainable Energy Reviews 2017;73:1352-65.

[13] Amin M, Putra N, Kosasih EA, Prawiro E, Luanto RA, Mahlia TMI. Thermal properties of beeswax/graphene phase change material as energy storage for building applications. Applied Thermal Engineering 2017;112:273-80.

[14] Atabani AE, Silitonga AS, Mahlia TMI. Cost benefit analysis and environmental impact of fuel economy standards for passenger cars in Indonesia. Renewable and Sustainable Energy Reviews 2012;16:3547-58.

[15] Silitonga AS, Atabani AE, Mahlia TMI, Sebayang AH. Techno-economic analysis 
and environmental impact of fuel economy labels for passenger cars in Indonesia. Renewable and Sustainable Energy Reviews 2011;15:5212-7.

[16] Ketenagalistrikan DJ. Statistik Ketenagalistrikan 2015. 2016.

[17] Warjito, Adanta D, Budiarso, Prakoso AP. The effect of bucketnumber on breastshot waterwheel performance. IOP Conference Series: Earth and Environmental Science, vol. 105, IOP Publishing; 2018, p. 12031.

[18] Adanta D, Budiarso, Warjito, Siswantara AI. Assessment of Turbulence Modelling for Numerical Simulations into Pico Hydro Turbine. Journal of Advanced Research in Fluid Mechanics and Thermal Sciences 2018;45:21-31.

[19] PLN PT. Rencana Usaha Penyediaan Tenaga Listrik (RUPTL) 2015-2024. Jakarta: PT PLN (Persero) 2015.

[20] Bozhinova S, Kisliakov D, Müller G, Hecht V, Schneider S. Hydropower converters with head differences below 2. 5 m. Proceedings of ICE: Energy 2013;166:107-19.

[21] Quaranta E, Müller G. Sagebien and Zuppinger water wheels for very low head hydropower applications. Journal of Hydraulic Research 2018:1-11.

[22] Harinaldi, Budiarso. Sistem Fluida (Prinsip Dasar dan Penerapan Mesin Fluida, Sistem hidrolik dan Sistem Pnuematik). Jakarta: Erlangga; 2015.

[23] Nasution SB, Budiarso, Warjito, Adanta D. A Comparison of Openflume Turbine Designs with Specific Speeds (Ns) Based on Power and Discharge Functions. Journal of Advanced Research in Fluid Mechanics and Thermal Sciences 2018;45:53-60.

[24] Ho-Yan B. Design of a low head pico hydro turbine for rural electrification in Cameroon 2012.

[25] Williams AA, Simpson R. Pico hydro-Reducing technical risks for rural electrification. Renewable Energy 2009;34:1986-91.

[26] Ramos HM, Simão M, Borga A. Experiments and CFD analyses for a new reaction microhydro propeller with five blades. Journal of Energy Engineering 2012;139:109_ 17.

[27] Vicente S, Bludszuweit H. Flexible design of a pico-hydropower system for Laos communities. Renewable Energy 2012;44:406-13.

[28] Amromin EL. Design approach for cavitation tolerant hydrofoils and blades. Journal of Fluids and Structures 2014;45:96-106.

[29] Simpson RG, Williams AA. Application of computational fluid dynamics to the design of pico propeller turbines. Proceedings of the international conference on renewable energy for developing countries, University of the District of Columbia Washington, DC; 2006.

[30] Arrieta C, Lenin E, Agudelo Flórez S, Sierra NI. Application of CFD to the design of the runner of a propeller turbine for small hydroelectric power plants. Revista Facultad de Ingeniería Universidad de Antioquia 2013:181-92.

[31] Alexander K V, Giddens EP, Fuller AM. Axial-flow turbines for low head microhydro systems. Renewable Energy 2009;34:35-47.

[32] Singh P, Nestmann F. Experimental investigation of the influence of blade height and blade number on the performance of low head axial flow turbines. Renewable Energy 2011;36:272-81.

[33] Swiderski J, Martin JN, Norrena R. Automated runner blade design optimization process based on CFD verification. Parameters 2001;11:n11.

[34] Ramos HM, Borga A, Simão M. New design solutions for low-power energy 
production in water pipe systems. Water Science and Engineering 2009;2:69-84.

[35] Božić I, Benišek M. An improved formula for determination of secondary energy losses in the runner of Kaplan turbine. Renewable Energy 2016;94:537-46.

[36] Nechleba M. Hydraulic turbines, their design and equipement 1957.

[37] Othman MM, Razak JA, Bashar MF, Muhammad NS, Sopian K. CFD Analysis on The Flat Runner Blades of Propeller's Turbine under Low Head and Low Flow Condition. Applied Mechanics \& Materials 2014;699.

[38] Ardian Syah. Manual Pembangunan PLTMH - Tri Mumpuni. Jakarta: Japan International Cooperation Agency; 2017.

[39] Gubin MF. Draft tubes of hydro-electric stations. Published for the Bureau of Reclamation, US Dept. of the Interior and National Science Foundation, Washington, DC by Amerind Pub. Co.; 1973.

[40] Adanta D, Budiarso, Warjito, Siswantara AI, Prakoso AP. Performance Comparison of NACA 6509 and 6712 on Pico Hydro Type Cross-Flow Turbine by Numerical Method. Journal of Advanced Research in Fluid Mechanics and Thermal Sciences 2018;45:116-27.

[41] A. Revell. Advanced Aerodynamics Part 2: Turbulence Modelling \& Simulation (L2: 526 Viscous flow and turbulence) n.d.

[42] Slater JW. Examining spatial (grid) convergence. Public Tutorial on CFD Verification and Validation, NASA Glenn Research Centre, MS 2006;86.

[43] Roache PJ. Quantification of uncertainty in computational fluid dynamics. Annual Review of Fluid Mechanics 1997;29:123-60.

[44] Roache PJ. Verification and validation in computational science and engineering. Hermosa; 1998.

[45] Adhikari P, Budhathoki U, Timilsina SR, Manandhar S, Bajracharya TR. A Study on Developing Pico Propeller Turbine for Low Head Micro Hydropower Plants in Nepal. Journal of the Institute of Engineering 2014;9:36-53.

[46] Ramos HM, Simão M, Borga A. CFD and experimental study in the optimization of an energy converter for low heads. Energy Science and Technology 2012;4:69-84. 